\title{
Evaluation of the phytochemical content, antimicrobial and antioxidant activity of Cocos nucifera liquid smoke, Garcinia mangostana pericarp, Syzygium aromaticum leaf, and Phyllanthus niruri L. extracts
}

\author{
Tiurma Pasaribu(D), Arnold P. Sinurat (D), Elizabeth Wina(i) and Triwardhani Cahyaningsih (iD) \\ Division of Nutrition and Agrostology, Indonesian Research Institute For Animal Production, Ciawi Bogor 16720, \\ Indonesia. \\ Corresponding author: Tiurma Pasaribu, e-mail: pasaributiurma@yahoo.com \\ Co-authors: APS: arnoldps57@yahoo.com, EW: winabudi@yahoo.com, TC: ctriwardhani@yahoo.com \\ Received: 05-07-2021, Accepted: 14-10-2021, Published online: 29-11-2021
}

doi: www.doi.org/10.14202/vetworld.2021.3048-3055 How to cite this article: Pasaribu T, Sinurat AP, Wina E, Cahyaningsih T (2021) Evaluation of the phytochemical content, antimicrobial and antioxidant activity of Cocos nucifera liquid smoke, Garcinia mangostana pericarp, Syzygium aromaticum leaf, and Phyllanthus niruri L. extracts, Veterinary World, 14(11): 3048-3055.

\begin{abstract}
Background and Aim: Many plants contain bioactive substances with antibacterial and antifungal properties. The aim of this study was to evaluate the antibacterial and antifungal activity of Cocos nucifera shell liquid smoke (CSL), clove leaf extract (CLE), and mangosteen pericarp extract (MPE) alone and in combination against Escherichia coli and Candida utilis. The antioxidant activity, phenol, saponin, and tannin of CSL, CLE, MPE, and Phyllanthus niruri L. extract were also measured.

Materials and Methods: The agar well-diffusion method was used to determine the antimicrobial and antifungal activities of CSL, methanolic MPE, and CLE and their combination CSL+MPE+CLE (COMBI) on bacteria E. coli and fungus (C. utilis). Antioxidant activity was measured by the diphenylpicrylhydrazyl method. Total phenol and total tannin were measured by the Folin-Ciocalteu method and total saponin was measured by the vanillin-sulphate method.

Results: The results indicated that phenolic and tannin levels were greater in MPE than in CLE, whereas the saponin content was higher in CLE compared with MPE. Undiluted (100\%) MPE exhibited lower antibacterial activity $(p<0.05)$ than chloramphenicol against E. coli, however, undiluted CLE and COMBI showed similar activity compared with chloramphenicol against E. coli. COMBI caused significantly $(\mathrm{p}<0.05)$ higher inhibition compared with virginiamycin against E. coli. CSL, MPE, and COMBI exhibited significantly lower antifungal activity $(\mathrm{p}<0.05)$ than that of ketoconazole against $C$. utilis. In contrast, CLE showed improved antifungal activity $(\mathrm{p}<0.05)$ compared with ketoconazole.
\end{abstract}

Conclusion: Cocos nucifera liquid smoke, Garcinia mangostana pericarp extract, and Syzygium aromaticum leaf extract, either alone or in combination, have the potential to be used as antibacterial and antifungal agents.

Keywords: antibacterial, antifungal, Cocos nucifera, extract, Garcinia mangostana, Phyllanthus niruri L., Syzygium aromaticum.

\section{Introduction}

Agricultural feed additives are materials that do not contain nutrients, but aim to increase productivity, quality of livestock products (meat, eggs, milk, and fur), feed efficiency, and increase the immunity of livestock against disease. In some countries, feed additives that are widely used in the livestock industry belong to a class of antibiotics known as antibiotic growth promoters (AGPs). AGPs are added to minimize the population of pathogenic microbes in the digestive tract. In general, a provision of AGPs is to increase the growth of chickens by approximately 3.9\% and the feed efficiency by $2.9 \%$ [1]. Since January 2018, however, the use of AGPs has been banned in Indonesia to avoid

Copyright: Pasaribu, et al. Open Access. This article is distributed under the terms of the Creative Commons Attribution 4.0 International License (http://creativecommons.org/licenses/ by/4.0/), which permits unrestricted use, distribution, and reproduction in any medium, provided you give appropriate credit to the original author(s) and the source, provide a link to the Creative Commons license, and indicate if changes were made. The Creative Commons Public Domain Dedication waiver (http:// creativecommons.org/publicdomain/zero/1.0/) applies to the data made available in this article, unless otherwise stated. detrimental health effects to consumers, such as allergies and increasing number of drug-resistant microorganisms. European countries have banned the use of AGPs since 2006 [2]. Likewise, other countries, such as South Korea and the United States, have begun to limit AGP use. In 2019, there were more than 2.8 million people in the US suffering from infections, and there were 35,000 people who died from bacterial that was resistant to antibiotics [3]. There is a concern that this condition will increase if the use of AGPs is not controlled. In Indonesia, Noor and Poeloengan [4] reported that the use of antibiotics in animals was increased the resistance of Campylobacter and Salmonella bacteria to fluoroquinolone antibiotics and the third-generation antibiotics of cephalosporin. Antibiotics are generally given at a low dose (subtherapeutic level) at approximately 10-50 ppm [1]. Before AGPs were banned in 2018, the feed production in Indonesia was 18.2 million tons and it was calculated that the use of AGP would be around 182-910 tons/year. This amount will increase with the enhancement of feed production every year. However, this will increase the danger 
associated with resistance to antibiotics. However, the use of AGPs has been banned in Indonesia since 2018. Thus, an AGP alternative is needed, which is safer for livestock and the consumers of livestock products. In Europe, plant extracts have been used as a substitute for AGP [5]. Indonesia, as a tropical country, has a variety of plants containing bioactive compounds which may potentially serve as antibacterial and antifungal agents, such as Psidium guajava roots and leaves [6], cashew shell extract [7], mangosteen extract [8], Plumeria rubra flower and leaf extract [9], Phyllanthus niruri L. extract [10], and clove (Syzygium aromaticum) leaf extract [11].

We previously evaluated bioactive compounds from 12 plants and found three plant extracts that exhibit antibacterial, antifungal, and antioxidant properties (i.e., cashew nut shell liquid smoke, clove leaf extract [CLE], and mangosteen pericarp extract [MPE]) [12]. The combination of P. niruri L. and CLEs had the same ability to inhibit the growth of $E$. coli as the AGP, Zn bacitracin [13]. Although P. niruri extract exhibited the highest antioxidant activity, it is difficult to obtain enough quantity as it is a wild, non-cultivated plant. The MPE also contained high antioxidant activity [12] and is easier to obtain in large quantities. Other reports have shown that Cocos nucifera shell liquid smoke (CSL) also possesses antibacterial activities [14]. Since the coconut shell is abundant in Indonesia, the production of its liquid smoke is easier and cheaper than Anacardium occidentale shell liquid smoke. Therefore, a series of experiments was designed to produce a feed additive with antibacterial, antifungal, and antioxidant properties as an alternative to AGP consisting of the combination of CSL, MPE, and CLE (COMBI).

The aim of this study was to evaluate the phytochemical content, antibacterial and antifungal activity of CSL, mangosteen (Garcinia mangostana) pericarp extract, clove (S. aromaticum) leaf, P. niruri L. extract (PNE), and their combinations against Escherichia coli and Candida utilis.

\section{Materials and Methods}

\section{Ethical approval}

Ethical approval was not required for this study. All the experiments were performed in vitro.

\section{Study period and location}

The study was conducted from October 2020 to March 2021 in Microbiology Laboratory of Indonesian Research Institute for Animal Production, Bogor, West Java, Indonesia.

\section{Preparation of extract and liquid smoke}

Mangosteen (G. mangostana) pericarp was collected from Purworejo-Central Java and clove leaves (S. aromaticum) and P. niruri L. were collected from Bogor, West Java. Both plants are very common in Indonesia and public of Indonesia can identify it easily on the basis of gross characteristics. Both plants were identified by the authors. The rind of the mangosteen was washed using water, drained, then cut into small pieces of approximately $0.5-1 \mathrm{~cm}^{2}$. Mangosteen pericarp, clove leaves, and P. niruri L. were dried in an oven at $60^{\circ} \mathrm{C}$ for $4-5$ days. The dried mangosteen pericarp, clove leaves, and $P$. niruri L. were ground using a hammer mill, then screened using laboratory sieve No. 50 to obtain powder with a particle size of 300 microns.

One hundred and sixty grams of mangosteen pericarp, clove leaves, and/or P. niruri L. powder were mixed with $1440 \mathrm{~mL}$ of absolute methanol, placed in a shaker for $4 \mathrm{~h}$, left to stand overnight at $26^{\circ} \mathrm{C}$, and centrifuged at $10,000 \mathrm{RPM}$ for $10 \mathrm{~min}$ at $4^{\circ} \mathrm{C}$. The solution was filtered through filter paper and evaporated using a rotary evaporator at $40^{\circ} \mathrm{C}$. This process produced the MPE, CLE, and PNE. Cocos nucifera shell liquid smoke (CSL) was produced according to the procedure described by Pasaribu et al. [14].

A mixture of the three compounds, that is, CSL: MPE:CLE was made at a 1:1:1 ratio and this $100 \%$ stock mixture was designated an undiluted combination stock (COMBI).

\section{Antioxidant assay}

The antioxidant activity of two ingredients, MPE and PNE, was measured. The antioxidant capacity was determined based on the percentage of diphenylpicrylhydrazyl (DPPH) radical inhibition and Vitamin C was used as the standard. DPPH was measured according to the method described by Rusmana et al. [15] with minor modification. Briefly, $1 \mathrm{~mL}$ of extract solution was diluted with sterile distilled water at various dilutions (8000; 12,000; 16,000; and 20,000 times) and mixed with $2 \mathrm{~mL}$ DPPH methanolic solution. The mixture was vortexed and left to stand in the dark for $30 \mathrm{~min}$ and the absorbance was measured at $517 \mathrm{~nm}$. The radical scavenging activity was calculated by the following formula:

$$
\text { Scavenging } \%=(\mathrm{Ac}-\mathrm{As}) / \mathrm{Ac} \times 100
$$

Where, Ac is the negative control absorbance (without sample) and As is the sample absorbance.

The results were presented as $\mathrm{IC}_{50}$ values (sample concentration required to inhibit $50 \%$ radicals). The lower the $\mathrm{IC}_{50}$ value, the higher the antioxidant activity of the sample [16].

\section{Phytochemical determination}

Phytochemical (total phenol and saponin) content was measured for CSL, MPE, CLE, and PNE.

\section{Determination of total phenol}

Total phenolic content was determined in CSL, MPE, CLE, and PNE using the Folin-Ciocalteu method [17]. Briefly, $0.2 \mathrm{~g}$ of each sample was diluted into $10 \mathrm{~mL}$ of acetone $(70 \%)$ in a test tube, vortexed, and placed into an ultrasonic bath cleaner at $-5^{\circ} \mathrm{C}$ for $20 \mathrm{~min}$. The sample was diluted up to 50 times, $0.25 \mathrm{~mL}$ of Folin-Ciocalteu and $1.25 \mathrm{~mL}$ of $\mathrm{Na}_{2} \mathrm{CO}_{3} 20 \%$ ) were added, mixed by vortexing, and allowed to stand for $40 \mathrm{~min}$. The absorbance of the 
solution was read on a spectrophotometer at a wavelength of $725 \mathrm{~nm}$.

\section{Saponin determination}

Saponin content was measured in CSL, MPE, CLE, and PNE according to Hiai et al. [18]. Vanillin reagent $(1.6 \mathrm{~g})$ was added to $20 \mathrm{~mL}$ of absolute ethanol in a test tube and stirred. Plant extract $(0.25 \mathrm{~mL})$ was pipetted into a test tube, and $0.25 \mathrm{~mL}$ of vanillin reagent (fresh) and $2.5 \mathrm{~mL} 72 \% \mathrm{H}_{2} \mathrm{SO}_{4}$ (in cold temperature) were added. The mixture was heated in a water bath for $10 \mathrm{~min}$ at $60^{\circ} \mathrm{C}$ and cooled. The absorbance of the mixture was measured at a wavelength of $544 \mathrm{~nm}$. Diosgenin saponin was used as the reference standard.

Calculation: \%Saponin

$$
=\frac{(\mathrm{y}-\mathrm{a}) / \mathrm{b} \times \text { dilution factor } \times 10}{\text { Sample weight } \times 1000} \times 100
$$

Where, $y$ (absorbance); $\mathrm{a}$ and $\mathrm{b}$ (linear regression).

\section{Preparation of $E$. coli and $C$. utilis}

E. coli was inoculated into nutrient agar (NA) media and incubated overnight for antibacterial tests. C. utilis was inoculated into potato dextrose agar (PDA) media and incubated for 5 days for the antifungal test. The turbidity of E. coli and C. utilis was measured using a spectrophotometer at a wavelength of $620 \mathrm{~nm}$ with a concentration compared to a standard (0.5 McFarland).

\section{Antibacterial assay}

The antibacterial test was done by the agar well-diffusion method as described by Das et al. [19]. MPE, CLE, and COMBI were tested on NA media to measure the zone of inhibition against E. coli. E. coli was inoculated by spreading approximately $1 \mathrm{~mL}$ onto NA media with a cell count of 108 cells $/ \mathrm{mL}$, then leaving it for 4-5 min. The remaining liquid was pipetted and discarded. Four wells of $6 \mathrm{~mm}$ diameter were perforated into the agar medium with a sterile cork borer $(6 \mathrm{~mm})$ and filled with $60 \mu \mathrm{L}$ of plant extract (MPE/ CLE/COMBI) using a micropipette in each well under aseptic conditions. The MPE and CLE were diluted with sterile distilled water at different concentration, that is, $10 \%, 20 \%, 30 \%, 40 \%, 50 \%, 60 \%, 70 \%, 80 \%$, $90 \%$, and $100 \%$ (no dilution). Antibiotic (chloramphenicol, $18 \mathrm{ppm}$ ) was used as a positive control and sterile distilled water was used as a negative control. COMBI was also diluted to a range of concentrations $(6.25 \%, 12.50 \%, 25 \%, 50 \%, 75 \%$, and $100 \%)$. Two positive controls were established (i.e., virginiamycin $40 \mathrm{ppm}\left[\mathrm{K}^{+1}\right]$ and chloramphenicol $30 \mathrm{ppm}\left[\mathrm{K}^{+2}\right]$ ).

\section{Antifungal assay}

The antifungal test was carried out by an agar well-diffusion method as described by Ubulom et al. [20]. CSL, MPE, CLE, and COMBI were tested on PDA media to measure the zone of inhibition against $C$. utilis. C. utilis was inoculated by spreading approximately $1 \mathrm{~mL}$ onto PDA media with a cell count of $10^{8} / \mathrm{mL}$, then leaving for $4-5 \mathrm{~min}$. The remaining liquid was pipetted and discarded. Four wells of $6 \mathrm{~mm}$ diameter were perforated into the agar medium with a sterile cork borer $(6 \mathrm{~mm})$ and filled with $30 \mu \mathrm{L}$ of plant extract (MPE/CLE/COMBI) using a micropipette for each well under aseptic conditions. MPE and CLE were diluted with sterile distilled water to establish a range of concentrations $(10 \%, 20 \%, 30 \%, 40 \%, 50 \%$, $60 \%, 70 \%, 80 \%, 90 \%$, and $100 \%$ ). Antifungal ketoconazole $(30 \mathrm{mg} / \mathrm{mL})$ was used as a positive control and sterile distilled water was used as a negative control. COMBI was also diluted to a range of concentrations $(10 \%, 20 \%, 40 \%, 60 \%, 80 \%$, and $100 \%)$.

Overall, the properties measured in this study included antioxidant activity; phytochemical analysis (total phenols, saponins, and tannins) of MPE, CLE, PNE, and COMBI; antibacterial activity of MPE, CLE, and COMBI against E. coli; and antifungal activity of CSL, MPE, CLE, and COMBI against $C$. utilis.

\section{Statistical analysis}

All data were statistically analyzed using a oneway analysis of variance (ANOVA). Duncan tests were performed if the ANOVA showed significant differences $(p<0.05)$. Assays were replicated 4 times and the values are expressed as the mean \pm standard error.

\section{Results and Discussion}

\section{Antioxidant activity}

Antioxidants are substances that can prevent or slow down damage to cells of organisms resulting from free radicals. A commonly used antioxidant is ascorbic acid (Vitamin C). $\mathrm{IC}_{50}$ values are commonly used as an indicator of antioxidant activity, which is the concentration of a substance that reduces DPPH free radicals by $50 \%$. The lower the $\mathrm{IC}_{50}$ value, the higher the antioxidant activity [16].

The results showed that the $\mathrm{IC}_{50}$ value of G. mangostana pericarp extract was lower $(0.05 \mu \mathrm{L} / \mathrm{mL})$ compared with that of PNE $(0.10 \mu \mathrm{L} / \mathrm{mL})$ and the phenol content of $G$. mangostana pericarp extract was higher $(12.09 \%)$ than that of PNE (3.78\%) (Table-1). However, our previous results [12] indicated that the antioxidant capacity of PNE was slightly higher than that of MPE. The phenol content of MPE (12.09\%) was higher than PNE (3.78\%). This indicates that the phenol content exhibits a positive correlation with antioxidant activity. Plants that are rich in phenolic compounds are known to be good sources of natural antioxidants [21].

\section{Phytochemical compounds}

The highest total phenol and tannin content was found in MPE, whereas the lowest was in CSL. The highest saponin content was present in CLE (Table-2).

Table-1: Antioxidant activity $\left(\mathrm{IC}_{50}\right.$ ) of MPE and PNE.

\begin{tabular}{lc}
\hline Source of antioxidant & IC $_{\mathbf{5 0}}(\boldsymbol{\mu L} / \mathbf{m L})$ \\
\hline MPE & 0.05 \\
PNE & 0.10 \\
\hline
\end{tabular}

$\mathrm{MPE}=$ Mangosteen pericarp extract, $\mathrm{PNE}=$ Phyllanthus niruri L. extract 
Phytochemical compounds of $C$. nucifera shell liquid smoke consist of aldehyde, ketone, organic acid, alcohol, ester 2-propanone, acetic acid, methanol, 2-butanone, 2-propanone, 1-hydroxy-2 butanone, furancarboxaldehyde, phenol, benzene, and acetic acid as the most prominent [22]. This indicates that there were only a few phenolic compounds in CSL, which was in accordance with the results of the analysis (Table-2).

The pericarp of G. mangostana contains flavonoids, tannins, prenylated xanthones, benzophenones, bioflavonoids, triterpenes, and over 68 xanthone-type constituents [23-25]. The most prominent is $\alpha$-mangostin [26].

Qualitatively, the CLE contains alkaloids, flavonoids, saponins, tannins, steroids, triterpenoids, and phenolics [27]. The main phytochemical components in clove extract were eugenol $(63 \%-85 \%)$, eugenyl acetate (15\%), caryophyllene (13.97\%), and phenol, 2-methoxy-4-(2-propenyl), acetate $(12.72 \%)$, and $\beta$-caryophyllene $(5.12 \%)[28,29]$. The aforementioned findings are in accordance with the results of the present study in which the phenol content in CLE was determined to be relatively low (i.e., 11.51\%). Although the most abundant phytochemical in P. niruri was phyllanthin, the phenol content was low at 3.78\%. To date, information regarding the tannin content of CSL, mangosteen pericarp, and clove leaves is limited.

Phenol, saponins, and tannins in COMBI at different dilution ratios were also measured to determine whether dilution had an effect on the phytochemical compounds. The phytochemical compounds of COMBI at a range of $10-100 \%$ showed that the higher the concentration, the higher the content of total phenols, saponins, and tannins (Table-3). Saponin content was higher compared with that of phenols and tannins in the COMBI. At all COMBI concentrations, the highest phytochemical content was saponins followed by phenols and tannins. This is in accordance with the levels in CSL, MPE, and CLE individually (Table-2) in which saponin levels were higher than phenols and tannins.

\section{Antibacterial activity of MPE and CLE}

The antibacterial activity of MPE and CLE individually at different dilutions was determined against E. coli (Table-4 and illustrated in Figures-1 and 2). The inhibition zone resulting from MPE and CLE is shown by the clear areas. The results indicated that the dilution ratio significantly $(p<0.01)$ affected the zone of inhibition against $E$. coli. There was no clear zone present when MPE was diluted from 1:9 to 4:6, but the clear zone appeared when MPE was present at higher concentrations (dilution ratio of 5:5 to undiluted). The zone of inhibition of undiluted MPE was significantly lower $(p<0.05)$ than that of chloramphenicol (18 ppm), with a clear zone of $11.75 \mathrm{~mm}$ and $13.75 \mathrm{~mm}$, respectively (Table-4). The zone of inhibition of MPE against $E$. coli was not significant $(\mathrm{p}>0.05)$ when MPE was diluted with distilled water
Table-2: Total phenol, saponin, and tannin content in CSL, MPE, CLE, and PNE.

\begin{tabular}{lccc}
\hline Ingredients & $\begin{array}{c}\text { Total } \\
\text { phenol (\%) }\end{array}$ & Saponin (\%) & Tannin (\%) \\
\hline CSL & 1.24 & 1.36 & 0.48 \\
MPE & 12.09 & 34.19 & 9.85 \\
CLE & 11.51 & 57.27 & 2.24 \\
PNE & 3.78 & 5.75 & 2.68 \\
\hline
\end{tabular}

$\mathrm{CSL}=$ Cocos nucifera shell liquid smoke, $\mathrm{MPE}=$ Mangosteen pericarp extract, $\mathrm{CLE}=$ Clove leaves extract,

$\mathrm{PNE}=$ Phyllanthus niruri extract

Table-3: Total phenol, saponin, and tannin content in COMBI with different dilutions.

\begin{tabular}{lccc}
\hline Ratios & $\begin{array}{c}\text { Total } \\
\text { phenol }\end{array}$ & Tannin & Saponin \\
\hline Dilution ratio & $(\mathrm{g} / 100 \mathrm{~mL})$ & $(\mathrm{g} / 100 \mathrm{~mL})$ & $(\mathrm{g} / 100 \mathrm{~mL})$ \\
$1: 9$ & 0.11 & 0.07 & 1.17 \\
$2: 8$ & 0.27 & 0.17 & 1.52 \\
$3: 7$ & 0.28 & 0.19 & 2.25 \\
$4: 6$ & 0.69 & 0.41 & 2.36 \\
$5: 5$ & 1.15 & 0.80 & 3.10 \\
$6: 4$ & 1.54 & 0.99 & 8.41 \\
$7: 3$ & 1.45 & 0.96 & 10.07 \\
$8: 2$ & 1.98 & 1.08 & 11.54 \\
$9: 1$ & 1.96 & 1.09 & 14.19 \\
Undiluted & 1.52 & 1.02 & 14.60 \\
\hline
\end{tabular}

COMBI=Combination of Cocos nucifera shell liquid smoke, mangosteen pericarp extract, clove leaves extract

Table-4: Inhibition zone (antibacterial activity) of MPE and CLE against Escherichia coli at different dilution ratios.

\begin{tabular}{lcc}
\hline $\begin{array}{l}\text { Dilution } \\
\text { ratios (extract: } \\
\text { sterile distilled } \\
\text { water) }\end{array}$ & \multicolumn{2}{c}{ Clear zone (mm) } \\
\cline { 2 - 3 } MPE & CLE \\
water) & & \\
$1: 9$ & $0.0+0.0^{\mathrm{e}}$ & $0.0+0.0^{\mathrm{g}}$ \\
$2: 8$ & $0.0+0.0^{\mathrm{e}}$ & $8.00+0.33^{\mathrm{d}}$ \\
$3: 7$ & $0.0+0.0^{\mathrm{e}}$ & $9.00+0.33^{\mathrm{cd}}$ \\
$4: 6$ & $0.0+0.0^{\mathrm{e}}$ & $9.25+0.58^{\mathrm{cd}}$ \\
$5: 5$ & $0.0+0.0^{\mathrm{e}}$ & $10.25+0.88^{\mathrm{bcd}}$ \\
$6: 4$ & $9.75+0.33^{\mathrm{d}}$ & $10.25+0.88^{\mathrm{bcd}}$ \\
$7: 3$ & $10.25+0.33^{\mathrm{cd}}$ & $11.25+1.0^{\mathrm{abc}}$ \\
$8: 2$ & $10.50+0.33^{\mathrm{c}}$ & $11.75+0.88^{\mathrm{ab}}$ \\
$9: 1$ & $10.75+0.33^{\mathrm{c}}$ & $13.00+0.88^{\mathrm{a}}$ \\
Undiluted & $11.50+0.00^{\mathrm{b}}$ & $13.00+0.88^{\mathrm{a}}$ \\
Chloramphenicol 18 & $11.75+0.33^{\mathrm{b}}$ & $13.00+0.33^{\mathrm{a}}$ \\
ppm $\left(\mathrm{K}^{+}\right)$ & $13.75+1.20^{\mathrm{a}}$ & $13.50+0.58^{\mathrm{a}}$ \\
p-value & & \\
\hline Dffferent superscript(a)e & $<0.001$ & $<0.001$ \\
\hline
\end{tabular}

Different superscript ${ }^{(\mathrm{a}-\mathrm{e})}$ within the same column indicates significantly different $(p<0.05)$. Data were means of four replicates \pm standard error. $\mathrm{MPE}=$ Mangosteen pericarp extract, $C L E=C l o v e$ leaf extract

at $6: 4,7: 3$, and 8:2 ratios, whereas a dilution ratio of 9:1 was not significantly ( $>>0.05$ ) different compared with undiluted MPE (Table-4). This indicates that MPE at a concentration of $50-100 \%$ was able to inhibit the growth of $E$. coli with an inhibition zone of $9.75-11.75 \mathrm{~mm}$. The results of this study are similar to that of Jacob et al. [30], who found the inhibition zone of G. mangostana pericarp extract to be $11 \mathrm{~mm}$. 
However, Permata et al. [31] reported a higher inhibition zone of MPE at $15.8 \mathrm{~mm}$.

The inhibition zone for CLE at a dilution ratio of 7:3 to undiluted was not significantly different $(\mathrm{p}>0.05)$ with those of chloramphenicol $(18 \mathrm{ppm})$ against $E$. coli, with a clear zone of 11.8-13.0 versus $13.5 \mathrm{~mm}$, respectively (Table-4). Unlike MPE, CLE exhibited growth inhibition of $E$. coli at a lower concentration from a dilution ratio of 1:9 to undiluted, with an inhibition zone of $8-13 \mathrm{~mm}$. This result indicates that CLE had similar activity to 18 ppm chloramphenicol. The results of this study were lower for the ethanol fraction of CLE, with an inhibition zone of $16.07 \mathrm{~mm}$ against $E$. coli, but similar for the n-hexane fraction, with an inhibition zone of $13.61 \mathrm{~mm}$, when compared with the results of Ramadhani et al. [27]. CLE at a concentration of $10-100 \%$ produced an inhibition zone against $E$. coli of 6.3-15.8 mm [11]. CLE at a concentration of $25 \%$ has also been reported to inhibit the growth of Salmonella typhi with an inhibition zone of approximately $16.90 \mathrm{~mm}$ [32].

At $100 \%$ concentration, the zone of inhibition of MPE against $E$. coli was approximately $11.75 \mathrm{~mm}$, whereas CLE was around $13 \mathrm{~mm}$ (Table-4) and CSL was around $22.88 \mathrm{~mm}$ (in press). This indicates that CLE is stronger than MPE, but CSL was still more active than CLE against $E$. coli.

Bioactive substances ( $\alpha$-mangostin, eugenol, and acetic acid) kill bacteria by damaging the cell membrane as a result of the reaction between phenolic compounds and cell wall phospholipids. As a result, the permeability of the cell membrane is disrupted which inhibits the function of mRNA and bacteria

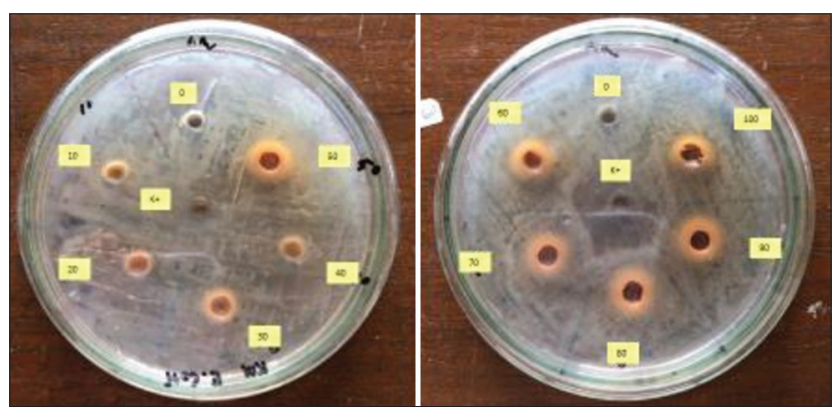

Figure-1: Inhibition zone of MPE at various concentrations against Escherichia coli.
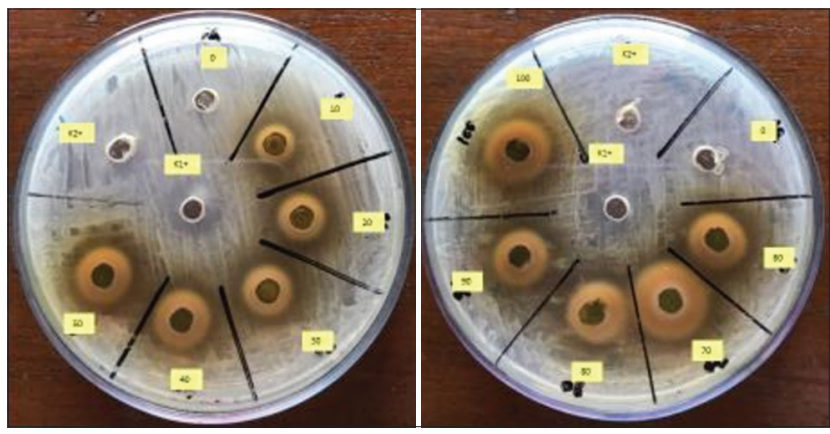

Figure-2: Clove leaf extract inhibition zone at various concentrations against Escherichia coli. development [33]. The acetic acid in CSL, which is protonated at low $\mathrm{pH}$, permeates the lipid bilayer of the cell wall and releases protons into the intracellular environment [34]. Thus, more damage to the cell walls occurs compared with eugenol of CLE and $\alpha$-mangostin of MPE. This indicates that acetic acid has a greater ability to inhibit the growth of pathogenic E. coli bacteria.

\section{Antibacterial activity of COMBI}

The antimicrobial activities of COMBI against E. coli at different concentrations are shown in Table-5 and Figure-3. The higher the COMBI concentration, the greater the zone of inhibition zone. Increased concentration of plant extracts causes greater cell membrane damage, so the inhibition zone is wider [35]. The wider zone of inhibition for $100 \%$ COMBI exhibited a greater destructive power because of the higher amount of bioactive substances penetrating into $E$. coli cells.

The efficacy of the antimicrobial activities of COMBI at a concentration of $6.25 \%$ was still able to inhibit the growth of $E$. coli, with an inhibition zone of $6.13 \mathrm{~mm}$. COMBI at $100 \%$ concentration equaled the inhibition zone of $30 \mathrm{ppm}$ chloramphenicol against E. coli, with values of $19.50 \mathrm{~mm}$ and $19.00 \mathrm{~mm}$, respectively. COMBI was more effective $(19.50 \mathrm{~mm})$ than virginiamycin $40 \mathrm{ppm}(6.25 \mathrm{~mm})$ against $E$. coli. This indicates that a mixture of CSL, MPE, and CLE is able to inhibit the growth of pathogenic bacteria. The CSL inhibition zone at a $100 \%$ concentration was approximately $22.88 \mathrm{~mm}$ (in press). It was $11.75 \mathrm{~mm}$ and $13 \mathrm{~mm}$ for MPE and CLE, respectively. This shows that the CSL inhibition zone was still greater compared with COMBI if used alone. In contrast, MPE and CLE individually exhibited inhibition zones that were smaller than COMBI.

The reduced effectiveness of COMBI (the combination of the three plants) occurred because MPE at a concentration of $10-40 \%$ could not inhibit the growth of E. coli, whereas CSL and CLE at a concentration of $10 \%$ inhibited the growth of E. coli. The main chemical component of CSL is acetic acid, whereas it is

Table-5: Inhibition zone (antibacterial activity) of COMBI against Escherichia coli.

\begin{tabular}{lc}
\hline Concentration & Clear zone ( $\mathbf{m m})$ \\
\hline 0 (sterile distilled water) & $0.0+0.0^{\mathrm{g}}$ \\
$6.25 \%$ & $6.71+0.18^{\mathrm{f}}$ \\
$12.50 \%$ & $9.21+0.26^{\mathrm{e}}$ \\
$25 \%$ & $12.86+0.28^{\mathrm{d}}$ \\
$50 \%$ & $16.14+0.50^{\mathrm{c}}$ \\
$75 \%$ & $17.97+0.05^{\mathrm{b}}$ \\
$100 \%$ (no dilution) & $19.50+0.19^{\mathrm{a}}$ \\
Virginiamycin 40 ppm & $6.68+0.16^{\mathrm{f}}$ \\
Chloramphenicol 30 ppm & $19.0+0.29^{\mathrm{a}}$ \\
p-value & $<0.001$ \\
\hline
\end{tabular}

Different superscript ${ }^{(\mathrm{a}-\mathrm{g})}$ within the same column indicates significantly different $(p<0.05)$. Data were means of seven replicates \pm standard error. COMBI $=$ Combination of Cocos nucifera shell liquid smoke, mangosteen pericarp extract, clove leaves extract 
$\alpha$-mangostin in MPE and eugenol in CLE, which indicates that the combination could still inhibit E. coli growth. These findings also indicate that the bioactive substances in COMBI, which predominantly damage the cell membrane of E. coli, are acetic acid and eugenol.

\section{Antifungal activity of CSL, MPE, and CLE}

The antifungal activity of CSL, MPE, and CLE on $C$. utilis is shown in Table-6. CSL at a concentration of $100 \%$ was significantly $(\mathrm{p}<0.05)$ less effective than ketoconazole at inhibiting the growth of $C$. utilis (7.50 $\mathrm{mm}$ vs. $16.75 \mathrm{~mm}$ ) (Table-6). However, CSL was still able to inhibit the growth of $C$. utilis at a concentration of $80-100 \%$, yielding a zone of inhibition of 6.50-7.50 mm. The predominant component, acetic acid, from CSL damages the cell walls of the $C$. utilis fungus so that its growth is disrupted. Using the

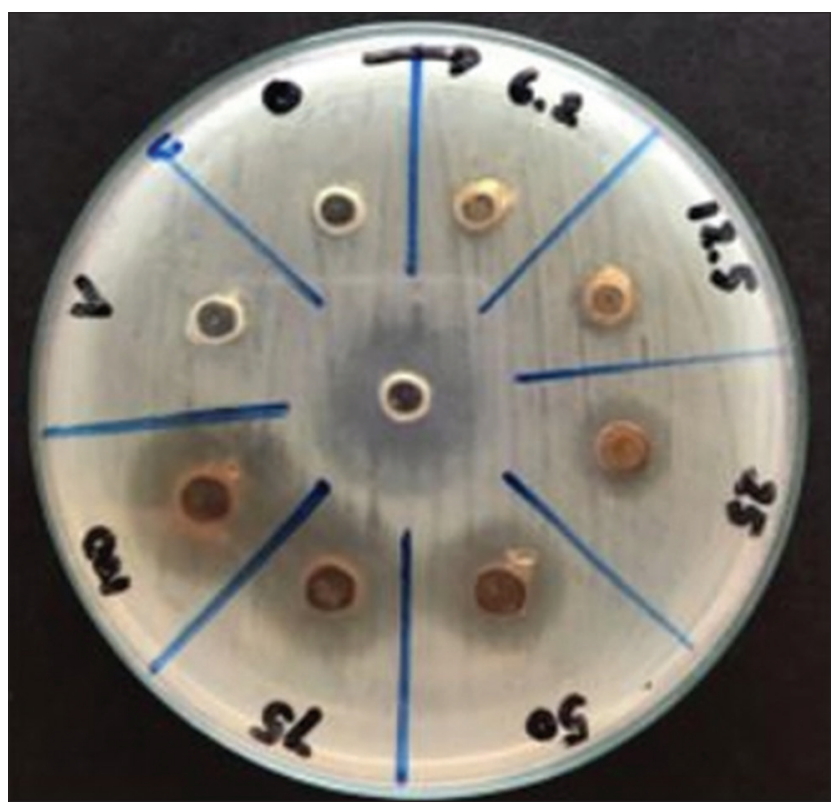

Figure-3: Antibacterial activity of combination of Cocos nucifera shell liquid smoke, mangosteen pericarp extract, and clove leaves extract at concentrations against Escherichia coli. microplate reader method, CSL inhibited the growth of C. utilis by up to $86.8 \%$ [14]. In contrast, there was no antifungal effect of CSL on Candida spp. [36]. This indicates that the antimicrobial activity of CSL was more effective on E. coli than C. utilis.

Similarly, MPE at a concentration of $100 \%$ was significantly $(\mathrm{p}<0.05)$ less effective than ketoconazole at inhibiting the growth of $C$. utilis (12.50 vs. $14.75 \mathrm{~mm}$ ) (Table-6). However, MPE at a concentration of $20-100 \%$ was able to inhibit the growth of C. utilis, with an inhibition zone of approximately 8.0$12.50 \mathrm{~mm}$. The inhibition zone for MPE against C. utilis was not significantly ( $>0.05)$ different at concentrations ranging from $40 \%$ to $90 \%$. The effect of MPE on the inhibition zone of C. utilis was minimal at a concentration of $20 \%$, which indicates that if the concentration was below 20\%, MPE would be ineffective at inhibiting the growth of C. utilis. According to Geetha et al. [8], the inhibition zone of mangosteen fruit extract against $C$. utilis was $9 \mathrm{~mm}$. Data on the effect of MPE on $C$. utilis have not yet become available.

The inhibition zone for CLE at $100 \%$ concentration was significantly $(\mathrm{p}<0.05)$ greater compared with that of ketoconazole $(21.25 \mathrm{~mm}$ and $16.0 \mathrm{~mm}$, respectively) (Table-6). CLE at a concentration of $10 \%$ was able to inhibit the growth of $C$. utilis with an inhibition zone of approximately 6.38. CLE inhibited the growth of Candida albicans, whereas clove oil exhibited robust antifungal activity [37,38]. Data on the effect of CLE on C. utilis are still limited.

The results showed that CLE exhibited the highest growth inhibitory effect against $C$. utilis when compared with MPE and CSL. The bioactive substance, eugenol, in CLE was more effective than $\alpha$-mangostin from MPE and acetic acid from CSL to damage the cell walls and disrupt the growth of $C$. utilis fungi.

\section{Antifungal activity of the CSL, MPE, and CLE combination}

The COMBI inhibition zone at $100 \%$ concentration was significantly lower $(\mathrm{p}<0.05)$ than that of

Table-6: Antifungal activity of CSL, MPE, and CLE and their combination in various concentrations against Candida utilis.

\begin{tabular}{|c|c|c|c|c|}
\hline \multirow[t]{2}{*}{ Concentration } & \multicolumn{4}{|c|}{ Inhibition zone (mm) } \\
\hline & CSL & MPE & CLE & COMBI \\
\hline 0 (sterile distilled water) & $0.0+0.0^{d}$ & $0.0+0.0^{g}$ & $0.0+0.0^{f}$ & $0.0+0.0^{d}$ \\
\hline $10 \%$ & $0.0+0.0^{d}$ & $0.0+0.0^{g}$ & $6.38+0.13^{e}$ & $0.0+0.0^{d}$ \\
\hline $20 \%$ & $0.0+0.0^{d}$ & $8.0+0.41^{f}$ & $13.25+0.63^{d}$ & $0.0+0.0^{d}$ \\
\hline $30 \%$ & $0.0+0.0^{d}$ & $9.25+0.25^{\mathrm{e}}$ & $13.75+0.63^{d}$ & - \\
\hline $40 \%$ & $0.0+0.0^{d}$ & $10.0+0.41 d^{e}$ & $14.50+1.19^{c d}$ & $9.50+0.87^{c}$ \\
\hline $50 \%$ & $0.0+0.0^{d}$ & $10.25+0.48^{\text {cde }}$ & $15.50+0.29 c$ & - \\
\hline $60 \%$ & $0.0+0.0^{d}$ & $10.50+0.25^{\mathrm{dc}}$ & $18.50+0.65^{b}$ & $10.75+0.48^{\mathrm{bc}}$ \\
\hline $70 \%$ & $0.0+0.0^{d}$ & $10.75+0.29 \mathrm{dc}$ & $19.75+0.25^{\mathrm{ab}}$ & - \\
\hline $80 \%$ & $6.50+0.50^{c}$ & $10.75+0.25^{\mathrm{dc}}$ & $20.75+0.25^{a}$ & $11.50+0.87^{b}$ \\
\hline $90 \%$ & $7.50+0.50^{b}$ & $11.25+0.25^{c}$ & $21.00+0.41^{a}$ & - \\
\hline $100 \%$ & $7.50+0.50^{b}$ & $12.50+0.65^{b}$ & $21.25+0.25^{a}$ & $11.75+0.48^{b}$ \\
\hline Ketoconazole (30 mg/mL) & $16.75+0.63^{a}$ & $14.75+0.25^{a}$ & $16.0+0.25^{c}$ & $15.50+0.029^{a}$ \\
\hline p-value & $<0.001$ & $<0.001$ & $<0.001$ & $<0.001$ \\
\hline
\end{tabular}

Different superscript ${ }^{(\mathrm{a}-\mathrm{g})}$ within the same column indicates significantly different $(\mathrm{p}<0.05)$. Data were means of four replicates \pm standard error. $\mathrm{CLS}=$ Cocos nucifera shell liquid smoke, MPE=Mangosteen pericarp extract, $C L E=C l o v e ~ l e a v e s$ extract, $\mathrm{COMBI}=$ Combination of CLS, MPE, and CLE 
ketoconazole (Table-6); however, COMBI was able to inhibit $C$. utilis $(9.5 \mathrm{~mm})$ at a minimum concentration of $40 \%$. At a concentration of $80-100 \%$, the COMBI inhibition zone $(11.5-11.75 \mathrm{~mm})$ was significantly $(\mathrm{p}<0.05)$ greater compared with a concentration of $40 \%$. When each extract was tested against C. utilis individually, the minimum inhibition zone for CSL occurred at a concentration of $80 \%$. The minimum concentration was $20 \%$ and $10 \%$ for MPE and CLE, respectively. This indicates that the effectiveness of CSL, MPE, and CLE was greater individually than in combination against $C$. utilis. Furthermore, $\alpha$-mangostin from MPE and eugenol from CLE had an important role in inhibiting the growth of $C$. utilis in the COMBI treatment. This indicates that the activity of plant extracts is better when used individually compared to treatment of a mixture of several plant extracts for inhibiting C. utilis growth.

Apart from being antibacterial and antifungal, phenols exhibit other properties, including antioxidant activity. The mechanism through which bioactive substances kill bacteria is similar, namely, by damaging cytoplasmic cell walls and nucleotides and disruption the cell membrane to inhibit DNA and protein synthesis $[39,40]$. These results indicate that the combination of MPE, CLE, and CSL could be used as an antifungal treatment to inhibit the growth of $C$. utilis.

\section{Conclusion}

The antioxidant activity of MPE was greater compared with that of PNE. Phenolic and tannin compounds were higher in MPE than in CLE, whereas the saponin compound was higher in CLE. Undiluted (100\%) MPE exhibited a significantly lower antibacterial activity than chloramphenicol against E. coli; however, undiluted CLE and COMBI exhibited similar antibacterial activity compared with chloramphenicol. The COMBI at a low concentration (6.25\%) showed similar antibacterial activity as $40 \mathrm{ppm}$ virginiamycin; however, the antifungal activity of COMBI occurred at a concentration $>40 \%$. In summary, $C$. nucifera liquid smoke, G. mangostana pericarp extract, and $S$. aromaticum leaf extract, either alone or in combination, have the potential to be used as antibacterial and antifungal treatments.

\section{Authors' Contributions}

TP: Conceived and wrote the manuscript. TP, APS, and EW: Revised the manuscript and carried out the research work. TP and TC: Performed the statistical analysis. All authors read and approved the final manuscript.

\section{Acknowledgments}

The authors are thankful to the Ministry of Research and Technology/National Research and Innovation Agency (KEMENRISTEK/BRIN) and Indonesia Endowment Fund for Education (LPDP), Indonesia, for funding this study (Grant no.:77/E1/
PRN/2020) and to The Indonesian Research Institute for Animal Production for providing necessary facilities for the study. Thanks to Helmi Hamid, Nila Miraya, and Eka Susilawati for help in the laboratory work.

\section{Competing Interests}

The authors declare that they have no competing interests.

\section{Publisher's Note}

Veterinary World remains neutral with regard to jurisdictional claims in published institutional affiliation.

\section{References}

1. Niewold, T. (2007) The nonantibiotic anti-inflammatory effect of an antimicrobial growth promoter, the real mode of action? A hypothesis. Poult. Sci., 86(4): 605-609.

2. Castanon, J.I.R. (2007) History of the use of antibiotic as growth promoters in European poultry feeds: Review. Poult. Sci., 86(11): 2466-2471.

3. Frieden, T. (2013) Antibiotic Resistance Threats in the United States, 2013. US. Department of Human Services. Centre for Diseases Control and Prevention, Sweden. p114.

4. Noor, S.M. and dan Poeloengan, M. (2005) Use of Antibiotics in Livestock and their Impact on Human Health. Proceedings of the National Workshop on Animal Food Safety, Bogor. p56-64.

5. Grashorn, M.A. (2010) Use of phytobiotics in broiler nutrition-an alternative to infeed antibiotics? J. Anim. Feed Sci., 19(3): 338-347.

6. Kidaha, M.L., Alakonya, A.E. and Nyende, A.B. (2013) Bioactivity determination of methanol and water extracts for roots and leaves of Kenyan Psidium guajava $L$ landraces against pathogenic bacteria. Springerplus, 2013(2): 670.

7. Sinurat, A.P., Pasaribu, T., Purwadaria, T., Haryati, T., Wina, E. and dan Wardhani, T. (2020) Biological evaluation of some plant bioactives as feed additives to replace antibiotic growth promoters in broiler feeds. J. Ilmu Ternak Vet., 25(2): 81-90.

8. Geetha, R.V., Lakshmi, T. and Roy, A. (2011) In vitro evaluation of antimycotic activity of ethanolic fruit extract of Garcinia mangostana Linn. Int. J. Curr. Res., 3(10): 28-32.

9. Pasaribu, T., Tobing, R.D.D., Kostaman, T. and Dewantoro, B. (2020) Active Substance Compounds and Antibacterial Activity of Extract Flower and Leaves of Plumeria rubra and Plumeria alba Against Escherichia coli. International Conference on Science and Applied Science (ICSAS 2020). Surakarta on July 7, 2020. Indonesia. AIP Conference Proceedings, Indonesia.

10. Chandana, G., Manasa, R., Vishwanath, S., Naik R.S. and Mahesh, M.S. (2020) Antimicrobial activity of Phyllanthus niruri (Chanka piedra). Review. IP J. Nut. Metabol. Health Sci., 3(4): 103-108.

11. Ugha, K.B., Rini, D.I. and dan Koamesah, S.M.J. (2019) Antibacterial activity test of clove (Syzygium aromaticum) leaf ethanol extract on the growth of Escherichia coli in vitro. Croatian Med. J., 7(2): 149-157.

12. Sinurat, A.P., Wina, E., Susana, I.W.R., Wardhani, T., Haryati, T. and Purwadaria, T. (2018) Bioactive substances of some herbals and their effectiveness as antioxidant, antibacterial, and antifungal. J. Ilmu Ternak Vet., 23(1): 18-27.

13. Pasaribu, T., Sinurat, A.P., Wina, E., Purwadaria, T., Haryati, T. and Susana, I.W.R. (2018) Effectiveness of bioactive combinations of several plant substances to inhibit the growth of Escherichia coli and Salmonella sp. J. Ilmu Ternak Vet., 23(3): 112-122.

14. Pasaribu, T. and Wina, E. (2017) Comparison of the Three 
Types of Liquid Smoke Activity Against Microbial Growth in vitro. Proceedings of the National Seminar on Animal Husbandry and Veterinary Technology "Animal and Veterinary Technology Supports Diversification of Animal Source of Protein", Bogor, Indonesia. p679-685.

15. Rusmana, D., Wahyudianingsih, R., Elisabeth, M., Balqis, B., Maesaroh, M. and Widowati, W. (2017) Antioxidant activity of Phyllanthus niruri extract, rutin and quercetin. Indones. Biomed. J., 9(2): 84-90.

16. Molyneux, P. (2004) The use of the stable free radical diphenylpicrylhydrazyl (DPPH) for estimating antioxidant activity. Songklanakarin J. Sci. Technol., 26(2): 211-219.

17. Şahin, S., Demir, C. and Malyer, H. (2011) Determination of phenolic compounds in Prunella L. by liquid chromatography-diode array detection. J. Pharm. Biomedic. Anal., 55(5): 1227-1230.

18. Hiai, S., Oura, H. and Nakajima, T. (1976) Color reaction of some sapogenins and saponins with vanillin sulfuric acid. Planta Med., 29(2): 116-122.

19. Das, D.C., Sinha, N.K., Chattopadhyay, J.C. and Das, M. (2013) Antibacterial activity and phytochemical analysis of Cardanthera difformis druce leaf extracts from West Bengal of India. Int. J. Phytomed., 5(4): 446-451.

20. Ubulom, P., Akpabio, E., Udobi, C.E. and Mbon, R. (2011) Antifungal activity of aqueous and ethanolic extracts of Picralima nitida seeds on Aspergillus flavus, Candida albicans and Microsporum canis. Res. Pharm. Biotechnol., 3(5): 57-60.

21. Maisuthisakul, P., Pasuk, S. and Ritthiruangdej, P. (2008) Relationship between antioxidant properties and chemical composition of some Thai plants. J. Food Compost. Anal., 21(3): 229-240.

22. Jayanudin and Suhendi, E. (2012) Identification of chemical components liquid smoke from coconut shell region Anyer Banten. J. Agrokoteknol., 4(1): 39-46.

23. Ji, X., Avula, B. and Khan, I.A. (2007) Quantitative and qualitative determination of six xanthones in Garcinia mangostana L. by LC-PDA and LC-ESI-MS. J. Pharm. Biomed. Anal., 43(4): 1270-1276.

24. Jung, H.A., Su, B.N., Keller, W.J., Mehta, R.G. and Kinghorn, A.D. (2006) Antioxidant xanthones from the pericarp of Garcinia mangostana (Mangosteen). J. Agric. Food Chem., 54(6): 2077-2082.

25. Shan, T., Ma, Q., Guo, K., Liu, J., Li, W., Wang, F. and $\mathrm{Wu}$, E. (2011) Xanthones from mangosteen extracts as natural chemopreventive agents: Potential anticancer drugs. Curr. Mol. Med., 11(8): 666-677.

26. Ragasa, C.Y., Tabin, T.J., Jo Madeleine Ann Reyes, J.M.A., Tan, M.C.S. and Shen, C.C. (2016) Chemical constituents of Garcinia mangostana pulp and seeds. Int. J. Pharm. Clin. Res., 8(8): 1166-1169.

27. Ramadhani, A., Saadah, S. and Sogandi, S. (2020) Antibacterial effect of clove leaf extract (Syzygium aromaticum) against Escherichia coli and Staphylococcus aureus. J. Bioteknol. Biosains Indones., 7(2): 203-214.

28. Kusalaruk, W. and Nakano, H. (2021) Hurdle effects of ethanolic plant extracts with antimicrobials commonly used in food against foodborne pathogenic Escherichia coli. Microbiol. Res., 2021(12): 288-298.

29. Mittal, M., Gupta, N., Parashar, P., Mehra, V. and Khatri, M. (2014) Evaluation and pharmacological activity of Syzygium aromaticum: A comprehensive review. Int. J. Pharm. Pharm. Sci., 6(8): 67-72.

30. Jacob, D.R., Nora Vigasini, N. and Iyer, P. (2016) Antibacterial activity of mangosteen (Garcinia mangostana) pericarp. World J. Pharm. Res., 5(9): 1797-1802.

31. Permata, P, Retno Kawuri, R. and dan Darmadi, A.A.K. (2018) Antibacterial test activity of ethanol extract manggis leaves (Gracinia mangostana L.) on growth of bacteria Escherichia coli. J. Simbiosis., 6(1): 7-11.

32. Ristiansyah, D.U., Yenita, Y., Melviana, M. and dan Annisa, A. (2018) Syzygium aromaticum leaf extract effectiveness test in vitro on the growth of Salmonella Typhi. $J$. Ibnu Sina Biomed., 2(1): 41-47.

33. Papuc, C., Goran, G.V., Predescu, C.N., Nicorescu, V. and Stefan, G. (2017) Plant polyphenols as antioxidant and antibacterial agents for shelf-life extension of meat and meat products: Classification, structures, sources, and action mechanisms. Comprehensive reviews. Food Sci. Food Saf., 16(6): 1243-1268.

34. Lund, P.A., De Biase, D., Liran, O., Scheler, O., Mira, N.P., Cetecioglu, Z., Fernández, E.N., Bover-Cid, S, Hall, R., Sauer, M. and O'Byrne, C. (2020) Understanding how microorganisms respond to acid $\mathrm{pH}$ is central to their control and successful exploitation. Front. Microbiol., 2020 (11): 1-8.

35. Thangiah, A.S., Obey, J. and Mutuku, N.C. (2013) Phytochemical analysis of Vernonia adoensis leaves and roots used as a traditional medicinal plant in Kenya. Int. $J$. Pharm. Biol. Sci., 3(3): 46-52.

36. Kailaku, S.I., Syakir, M., Mulyawanti, I. and Syah, A. (2017) Antimicrobial Activity of Coconut Shell Liquid Smoke. IOP Conference Series: Materials Science and Engineering, 29 $9^{\text {th }}$ Symposium of Malaysian Chemical Engineers (SOMChE), Miri, Sarawak, Malaysia. p1-7.

37. Chaieb, K., Zmantar, T., Ksouri, R., Hajlaoui, H., Mahdouani, K., Abdelly, C. and Bakhrouf, A. (2007) Antioxidant properties of the essential oil of Eugenia caryophyllata and its antifungal activity against a large number of clinical Candida species. Mycoses, 50(5): 403-406.

38. Riyanta, R.F.A. (2012) The antifungal effect of clove (Syzygium aromaticum (L.) leaf essential oil on the growth of the fungus Candida albicans. J. Impact Factor, 1(2): 1-4.

39. Lopez-Romero, J.C., González-Ríos, H., Borges, A. and Simões, M. (2015) Antibacterial effects and mode of action of selected essential oils components against Escherichia coli and Staphylococcus aureus. Evid. Based Complementary Altern. Med. 2015,(795435): 1-9.

40. Pinto, N.C.C., Silva, J.B., Menegati, L.M., Guedes, M.C.M., Marques, L.B., Da Silva, T.P., De Melo, R.C.N., De SouzaFagundes, E.M., Salvador, M.J., Scio, E. and Fabri, R.L. (2017) Cytotoxicity and bacterial membrane destabilization induced by Annona squamosa L. extracts. An. Acad. Bras. Cienc., 89(3): 2053-2073. 